\title{
INTEGRATING SUSTAINABLE DEVELOPMENT INTO THE ENGINEERING CURRICULUM
}

\author{
El Guemhioui, K; Baaziz, N \\ Department of Computer Science and Engineering, Université du Québec en Outaouais, Québec Canada
} karim@uqo.ca; nadia.baaziz@uqo.ca

\section{INTRODUCTION}

The Université du Québec en Outaouais (UQO), a small-sized university in the Ottawa-Gatineau area, is about to offer a new electrical engineering Bachelor degree that incorporates into the curriculum courses on earth-friendly technologies and energy efficiency, in a context of sustainable development. We expect UQO to be the first university in the province of Quebec to offer such a program. In this short paper, we present and discuss the key features of this new bachelor degree, relate the main problems that we had to overcome when shaping the program, and briefly reflect on the challenging issue of motivating students to bridge the gap between theory and practice by actually practicing sustainable engineering in their professional life.

\section{RATIONALE}

Sustainable development is a critical issue related to all human activities, and taken very seriously by a growing number of scientists. The international standard ISO 26000 on social responsibility, to be released in 2010, is aiming to offer guidance to public and private organisations on the application of sustainable development principles. Professional bodies, such as OIQ, are also concerned with this issue and advocate that the nature of engineering activities poises engineers to lead the way in this area. Even law makers are finally acting by passing legislation related to sustainable development (Loi sur le développement durable du Gouvernement du Québec, 2006). We strongly believe that the societal shift to sustainable development culture cannot occur without the active involvement of engineers. Therefore, engineering education must seize the momentum and start preparing future engineers to effectively integrate sustainable development considerations into their engineering projects. In North America, sustainability teachings are mainly confined to a graduate student audience ${ }^{1}$; the ÉTS of Montréal with its unique graduate program on renewable energies, open to engineers and non engineers alike, is no exception to this reality. Our belief that sustainability principles must be addressed in undergraduate engineering education guided us in shaping this new program.

\section{PROGRAM DESCRIPTION}

One of the main goals of our program is to prepare engineers that can systematically assess the impacts of technology on local and global populations and environments, and implement engineering solutions that minimize negative effect. To that effect, several learning strategies are used.

The mandatory courses of the new program consist of four blocks (see Figure 1). Block 1 comprises courses ensuring a traditional training in electrical engineering. The student acquires a strong foundation in electricity, electronics, thermodynamics, power electronics, electrical engineering, electrical networks, and control of industrial processes. The second block introduces the student to the concepts of sustainable development as an important part of the social responsibility of the professional engineer towards the environment and society. These skills prepare the student for the third block which contains more specialized courses on renewable energies, optimization of energy systems, operation and production management. It provides the student with good insight into electrical energy issues through the following lectures:

- Knowledge of conventional and sustainable energy technologies and infrastructures (hydro, solar-photovoltaic, solar-thermal, wind, biomass), energy efficiency and system profitability.

- Skill development in the field of optimization for decision making, theory and practice for problem formalization, modeling and simulation applied to energy systems.

- Student awareness regarding the increasing demand of expertise from energy industries making green turns.

- Presentation of the importance of productivity and quality in the management of an organisation's operations, impact of the human factor, mastering a set of techniques for planning, organisation and control options, strategy and process design to sustain competitive operations in organisations.

The fourth block addresses practical training. It adapts the concept of a vertically-integrated project scheme ${ }^{2}$ to the specifics of our department. Students spend their second summer doing field training in industry.

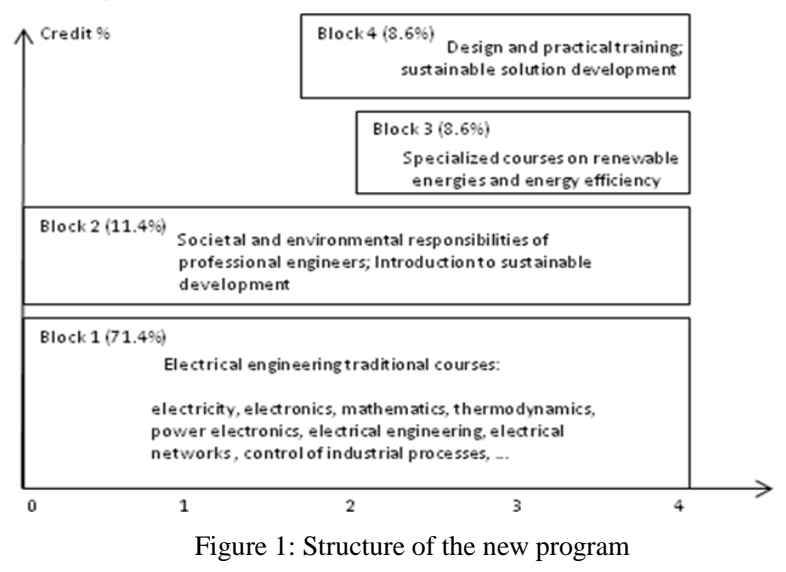

They are exposed to collaboration and multidisciplinarity through a project-oriented course in which they teamwork to design and implement an electrical engineering realisation. During their third summer, they complete a capstone junior project in industry. A capstone senior project concludes their studies. Of course all these activities are conducted under the close supervision of professors, members of a professional engineering body. These activities focus on synthesis and application of technical knowledge to solving open-ended problems. It is therefore expected that sustainable development considerations percolate into their electrical engineering practice to produce sustainable engineering solutions. To further enhance the students' experience of sustainable engineering in a real life and stringent context, we are considering to have projects conducted abroad in a similar way Rowan university $^{3}$ operates in collaboration with Engineers without Borders.

\section{DISCUSSION}

Among the challenges that we faced in preparing this new curriculum was the need to keep sharing as many core engineering courses with our existing computer engineering bachelor degree program, for the obvious reason of scarcity of professional and logistic resources, while still instilling sustainable development concepts and good practices into the new program. Furthermore, while there is a consensus that sustainable development cannot be achieved just by putting a social science course into an engineering curriculum, we could not just multiply sustainable engineering teachings and activities throughout the new program because we needed to ensure that the main goal is still met, that is graduating students with a solid mainstream electrical engineering background. We prioritized quality over quantity by making sustainability an integral element of the designing and implementation processes and by insisting on the key principle that technology-driven solutions must take into account the motives and desires of people who will be affected by them. Finally, for students to continue practicing sustainable engineering later as professionals, they need to understand and anticipate the benefits for future generations of what they are doing today.

\section{CONCLUSION}

It is clear that our program remains, after all, an electrical engineering bachelor degree that, though it emphasizes green energies and efficiency, cannot compete with programs whose main thrust is sustainability education. However, we are convinced that it will attract a new generation of brilliant youngsters who are turning their backs on scientific and engineering studies because they don't see how they could later be direct actors of changes in society.

\section{REFERENCES}

1. Prins R, Kander R, Moore T, Pappas E, Pierrakos O. Engineering for a sustainable world. $38^{\text {th }}$ ASEE/IEEE Proc. 2008;S2J-1-2

2.McBride TO, DeGoede K, Fullerton J. Sustainable engineering vertically-integrated project scheme in undergraduate engineering education. IEEE ISSST Proc. 2009;1-6

3.Sukamaran et al. A sustained effort for educating students about sustainable development. American Society for Eng. Educ. 2004;1-8 